\title{
Does finasteride treatment for benign prostatic hyperplasia influence sperm DNA integrity in dogs?
}

Daniel S. R. Angrimani', Luana C. Bicudo', Nuria Llamas Luceño², Bruno R. Rui ${ }^{1}$, Matheus F. Silva', João D. A. Losano', Bart Leemans², Ann Van Soom² and Camila I. Vannucchi ${ }^{1 *}$ (D)

\begin{abstract}
Background: Benign prostatic hyperplasia (BPH) is one of the most common reproductive disorders in both male dogs and men. Finasteride, a synthetic inhibitor of the enzyme 5a-reductase, is widely used as medical treatment. Although sperm can be affected by both BPH and finasteride treatment, the direct influence on DNA integrity remains unclear. Thus, the aim of this study was to verify the direct effect of $\mathrm{BPH}$ and/or finasteride treatment on DNA integrity of dog spermatozoa. A $2 \times 2$ factorial experiment was designed with 20 male dogs assigned to 4 experimental groups: BPH Group $(n=5)$, BPH-Finasteride Group $(n=5)$, Non-BPH Finasteride-Treated Group $(n=5)$ and Non-BPH Untreated Group $(n=5)$. Sperm evaluation was performed monthly for 60 days after the start of finasteride therapy or BPH diagnosis (D0, D30 and D60). Sperm DNA integrity was analyzed through fragmentation susceptibility (toluidine blue staining and Sperm Chromatic Structure Assay - SCSA), direct evaluation of DNA fragmentation (Sperm Chromatin Dispersion Assay - SCDA) and sperm protamination (chromomycin A3).
\end{abstract}

Results: Sperm DNA integrity was not affected by finasteride treatment. However, BPH dogs had higher susceptibility to sperm DNA acid denaturation (SCSA) compared to dogs not presenting BPH, as well as lower percentage of sperm with DNA integrity (toluidine blue staining).

Conclusion: In conclusion, benign prostatic hyperplasia causes post-testicular sperm DNA damage, albeit finasteride treatment itself does not directly influence sperm DNA integrity.

Keywords: Prostate, Canine, DNA fragmentation, Sperm, Finasteride

\footnotetext{
* Correspondence: cacavann@usp.br

1 Department of Animal Reproduction, School of Veterinary Medicine and Animal Science, University of São Paulo, Av. Prof. Orlando Marques de Paiva, 87, São Paulo 05508-270, Brazil

Full list of author information is available at the end of the article
}

(c) The Author(s). 2020 Open Access This article is licensed under a Creative Commons Attribution 4.0 International License, which permits use, sharing, adaptation, distribution and reproduction in any medium or format, as long as you give appropriate credit to the original author(s) and the source, provide a link to the Creative Commons licence, and indicate if changes were made. The images or other third party material in this article are included in the article's Creative Commons licence, unless indicated otherwise in a credit line to the material. If material is not included in the article's Creative Commons licence and your intended use is not permitted by statutory regulation or exceeds the permitted use, you will need to obtain permission directly from the copyright holder. To view a copy of this licence, visit http://creativecommons.org/licenses/by/4.0/ The Creative Commons Public Domain Dedication waiver (http://creativecommons.org/publicdomain/zero/1.0/) applies to the data made available in this article, unless otherwise stated in a credit line to the data. 


\section{Résumé}

Contexte: L'hyperplasie bénigne de la prostate (HBP) est l'un des troubles de la reproduction les plus courants chez le chien et chez l'homme. Le finastéride, un inhibiteur synthétique de l'enzyme 5a-réductase, est largement utilisé comme traitement médical. Bien que le sperme puisse être affecté à la fois par l'HBP et par le traitement avec le finastéride, l'influence directe sur l'intégrité de l'ADN reste peu claire. Le but de cette étude était ainsi de vérifier l'effet direct de l'HBP et/ou du traitement par finastéride sur l'intégrité de I'ADN des spermatozoïdes de chien. Dans la présente étude, 20 chiens mâles ont été randomisés selon un plan factoriel en 2x2 à l'un des 4 groupes expérimentaux suivants: Groupe HBP ( $n=5)$, Groupe HBP-Finastéride ( $n=5)$, Groupe non-HBP traité par Finastéride $(n=5)$, et Groupe non-HBP non traité $(n=5)$. L'analyse Le sperme a été réalisée mensuellement pendant 60 jours (J0, J30 et J60) soit après le début du traitement par finastéride ou à partir du diagnostic de HBP. L'intégrité de l'ADN des spermatozoïdes a été analysée par l'évaluation de la susceptibilité à la fragmentation (coloration au bleu de toluidine; détermination de la structure de la chromatine des spermatozoïdes - SCSA), par l'évaluation directe de la fragmentation de l'ADN des spermatozoïdes (détermination de la dispersion de la chromatine des spermatozoïdes - SCDA) et par l'évaluation de la protamination des spermatozoïdes (chromomycine A3).

Résultats: L'intégrité de l'ADN des spermatozoïdes n'a pas été affectée par le traitement par finastéride. Cependant, les chiens avec HBP ont une susceptibilité plus élevée à la dénaturation acide de l'ADN des spermatozoïdes (SCSA) par comparaison aux chiens ne présentant pas d'HBP, ainsi qu'un pourcentage plus bas de spermatozoïdes avec intégrité de l'ADN (coloration au bleu de toluidine).

Conclusions: L'hyperplasie bénigne de la prostate induit des altérations de l'ADN des spermatozoïdes, alors que le traitement par finastéride n'influence pas directement par lui-même l'intégrité de l'ADN des spermatozoïdes.

Mots-clés: Prostate, Chien, Fragmentation de I'ADN, Spermatozoïdes, Finastéride

\section{Background}

Benign prostatic hyperplasia (BPH) is a reproductive disorder of men and dogs $[1,2]$, with high prevalence in aged males $[3,4]$. The etiology of $\mathrm{BPH}$ is related to a hormonal imbalance between testosterone and estrogen and an increased activity of $5 \alpha$-reductase, leading to higher dihydrotestosterone (DHT) concentrations [5]. The overproduction of DHT induces prostatic cell proliferation, causing an abnormal enlargement of the prostate gland [6].

The hormonal imbalance and subsequent increase in prostate volume are associated with several reproductive clinical signs. Impaired spermatogenesis is often observed [7], which may affect sperm DNA integrity [8, 9]. Sperm DNA damage related to $\mathrm{BPH}$ was previously described in dogs [3] and men [4], albeit not yet completely elucidated. It is suggested that biochemical modifications of the prostatic fluid play an important role on sperm damage. Moreover, senescence and prostatic changes increase local oxidative stress, generating higher levels of reactive oxygen species and decreased antioxidant defense [10].

There are different forms to treat canine $\mathrm{BPH}$. Besides the existence of potent antiandrogen drugs (e.g., osaterone acetate), their availability is restricted to certain countries, limiting a world-wide prescription [11-13]. In dogs, orchiectomy is the permanent way to remove the androgenic stimulation of $\mathrm{BPH}$ [14], whereas finasteride, a synthetic inhibitor of the $5 \alpha$-reductase enzyme, is the most employed therapy for BPH in men [15]. Hence, finasteride can be used as an alternative for surgical treatment (orchiectomy) in breeding dogs with high genetic value, since previous studies have described little effect of finasteride on sperm quality (motility and morphology) and testosterone concentrations [16, 17]. Although Iguer-Ouada \& Verstegen [18] have attested the fertility of dogs under 20 weeks of finasteride treatment, in men, finasteride causes oligospermia or azoospermia and sperm DNA fragmentation [19, 20], related to a deleterious effect on spermatogenesis [19-21]. In addition, Vidigal et al. [22] showed reduced spermatogenesis and seminiferous tubules atrophy in finasteride treated hamsters.

DNA fragmentation has a dramatic effect on fertilization rates, embryonic development and embryo implantation [23-25]. Sperm chromatin damage has been associated with spermatogenesis failure or posttesticular disorders, likely related to reactive oxygen species-induced damage [26]. Thus, a deep-screening of sperm DNA integrity can suggest more precisely the origin of the chromatin damage [24]. Therefore, the aim of this study was to characterize the effects of $\mathrm{BPH}$ and finasteride therapy associated with structural abnormalities of sperm DNA in dogs. 


\section{Methods}

\section{Animals and experimental study}

This study was previously approved by the Bioethics Committee of the School of Veterinary Medicine and Animal Science - University of São Paulo (protocol number: 7122171213). All chemicals used in this study were obtained from Sigma-Aldrich (St. Louis, MO, USA) unless otherwise listed.

As described in detail previously, using the same study population [27], 20 male dogs of several breeds, aging from 5 to 13 years and weighting from 10 to $30 \mathrm{~kg}$ were selected for this study and assigned to four experimental groups:

(1) BPH Group $(n=5)$ : dogs with mean age of 10.8 years and body weight of $18.8 \mathrm{~kg}$ were presumptively diagnosed with $\mathrm{BPH}$ based on clinical signs (hematospermia, hematuria, pollakiuria, dysuria and tenesmus), marked prostatomegaly and prostatic biometry by B-mode ultrasound [28, 29].

(2) BPH-Finasteride Group $(n=5)$ : dogs with mean age of 9.2 years and body weight of $23.4 \mathrm{~kg}$ were presumptively diagnosed with $\mathrm{BPH}$ (as for the $\mathrm{BPH}$ Group) and subjected to BPH treatment with $5 \mathrm{mg}$ finasteride per animal, orally, every $24 \mathrm{~h}$ for 2 months [30].

(3) Non-BPH-Finasteride Group $(n=5)$ : dogs with mean age of 7.4 years and body weight of $20.8 \mathrm{~kg}$ without $\mathrm{BPH}$ were subjected to finasteride treatment protocol (as for the BPH-Finasteride Group). The diagnosis of BPH was ruled out by the lack of characteristic clinical signs coupled with a normal prostate morphometry by B-mode ultrasonography $[28,29]$.

(4) Non-BPH-Untreated Group (Control Group, $n=5$ ): dogs with mean age of 7.2 years and body weight of $22.3 \mathrm{~kg}$, not presenting BPH (as for the Non-BPHFinasteride Group) nor subjected to finasteride protocol.

To assure the appropriate sample size, an analysis was conducted with the SAS Power and Sample Size 12 (SAS Institute Inc., Cary, NC, EUA). A retrospective analysis of the data indicated there was a power of 0.99 , which is considered an acceptable statistical power (at least 0.8 ). Hence, a minimum of 5 dogs per group were sufficient to demonstrate significant differences in the data.

\section{Seminal collection}

Semen samples were collected monthly for 60 days, i.e., Day 0, Day 30 and Day 60, considering day 0 as the first day of finasteride treatment or BPH diagnosis. Semen was collected by penile digital manipulation directly into a calibrated plastic tube connected to a funnel. The sperm-rich fraction was collected by means of visual inspection of the ejaculate, as well as part of the 3rd fraction containing prostatic fluid. While collecting the sperm-rich fraction, we also included part of the prostatic fraction, as to achieve an equal proportion 1:1 of semen:prostatic fluid (v:v).

Subsequently, conventional sperm motility (\%) was assessed under light microscopy (Nikon, Eclipse E200, Japan) at $400 \times$ magnification using $5 \mu \mathrm{L}$ of semen placed on a pre-warmed glass slide with coverslip. Only dogs that showed total motility higher than $60 \%$ were included in this study. Then, the ejaculate was processed for sperm DNA integrity analysis.

\section{Evaluation of sperm susceptibility to DNA fragmentation Toluidine blue (TB) staining}

Semen smears were prepared and subjected to toluidine blue staining according to a protocol previously described by Rui et al. [31]. Smears were prepared with $10 \mu \mathrm{L}$ of the sperm sample on a glass slide and subsequently fixed in $96 \%$ ethanol-acetone for $30 \mathrm{~min}$ at $4{ }^{\circ} \mathrm{C}$. After drying, smears were hydrolyzed in $0.1 \mathrm{~N} \mathrm{HCl}$ for 5 min at $4{ }^{\circ} \mathrm{C}$ and washed three times in distilled water for $2 \mathrm{~min}$. Subsequently, smears were exposed to toluidine blue stain $(0.05 \%)$ for $20 \mathrm{~min}$ and washed 2 times in distilled water for $2 \mathrm{~min}$. Smears were evaluated under light microscopy (Leitz, Dialux 20, Germany) at 1000x magnification in a single-blind way, i.e., researchers were kept ignorant of either the group they were assessing. Sperm cells with damaged DNA were stained in blue, whereas intact DNA sperm remained unstained. For each sample, a minimum of 200 sperm cells were assessed and results were expressed in percentage (\%) of DNA damaged spermatozoa.

\section{Sperm chromatic structure assay (SCSA)}

The assay was performed following the methodology adapted by Lucio et al. [32] for dogs, based on a protocol that allows the estimation of chromatin susceptibility to acid denaturation [33]. Chromatin instability after acid exposure was quantified by flow cytometer after acridine orange (AO) labeling. Based on the DNA integrity status, a metachromatic fluorescence shift is induced from green (double-strand DNA) to red (denatured singlestrand DNA). We used the Guava EasyCyte ${ }^{\mathrm{ma}}$ Mini System (Guava ${ }^{\bullet}$ Technologies, Hayward, CA, USA), with a $488 \mathrm{~nm}$ argon laser and the following photodetector filters: PM1 (583 nm; yellow fluorescence), PM2 (680 $\mathrm{nm}$; red fluorescence) and PM3 $(525 \mathrm{~nm}$, green fluorescence). A total of 20,000 sperm cells were considered from each sperm sample and data were analyzed using Flow Jo v8.7 Software (Flow Cytometry Analysis Software - Tree Star Inc., Ashland, Oregon, USA). 
In brief, sperm samples $(15 \mu \mathrm{L})$ were diluted in $100 \mu \mathrm{L}$ TNE buffer $(0.01 \mathrm{M}$ Tris- $\mathrm{HCl}, 0.15 \mathrm{M} \mathrm{NaCl}, 1 \mathrm{mM}$ EDTA, pH 7.4) and subsequently mixed with $400 \mu \mathrm{L}$ of an acidified detergent solution $(0.08 \mathrm{M} \mathrm{HCl}, 0.1 \%$ Triton $\mathrm{X}-100,0.15 \mathrm{M} \mathrm{NaCl}, \mathrm{pH} 1.2)$. After $30 \mathrm{~s}$, sperm cells were stained by adding $600 \mu \mathrm{L}$ of $\mathrm{AO}$ staining solution (0.037 M citric acid, $0.126 \mathrm{M} \mathrm{Na}_{2} \mathrm{HPO}_{4}, 0.0011 \mathrm{M}$ disodium EDTA, $0.15 \mathrm{M} \mathrm{NaCl}$, pH 6.0). After $5 \mathrm{~min}$, samples were examined by flow cytometry as described above. DNA fragmentation rates were calculated based on the percentage of spermatozoa outside the main population in an $\alpha \mathrm{T}$ histogram (ratio between red fluorescence and total fluorescence) as evaluated using the Flow Jo system (Version Mac) [32, 34].

\section{Identification of DNA protamination by chromomycin A3 (CMA3)}

In order to identify defects on sperm protamination process, the chromomycin A3 technique was performed based on protocols previously described by Rahman et al. [35] and Simões et al. [36]. A positive control sample of deprotaminated dog sperm was prepared by exposing spermatozoa to a solution of $0.001 \%$ Triton X100 and $5 \mathrm{mM}$ DTT in $200 \mu \mathrm{L}$ phosphate buffered saline (PBS) for $15 \mathrm{~min}$, followed by incubation in a solution of $1 \mathrm{M} \mathrm{NaCl}$ and $5 \mathrm{mM}$ DTT in $\mathrm{H}_{2} \mathrm{O}$ for $2 \mathrm{~h}$. Subsequently, the positive control and all other tested sperm samples were washed in PBS and fixed in Carnoy's solution (3:1 methanol:acetic acid; Merck, Darmstadt, Germany) at $4{ }^{\circ} \mathrm{C}$ for $10 \mathrm{~min}$. Then, smears were prepared and subsequently treated with $12.5 \mu \mathrm{L}$ CMA3 solution $[0.25 \mathrm{mg} / \mathrm{ml}$ in $1000 \mu \mathrm{L}$ of Mcllvaine buffer $(7 \mathrm{ml}$ of $0.1 \mathrm{M}$ citric acid $+32.9 \mathrm{ml}$ of $\mathrm{Na}_{2} \mathrm{HPO}_{4} .7 \mathrm{H}_{2} \mathrm{O}, 2 \mathrm{M}$, $\mathrm{pH}$ 7.0, containing $10 \mathrm{mM} \mathrm{MgCl}$ )] for $20 \mathrm{~min}$. The slides were additionally stained for 2 to $5 \mathrm{~min}$ with Hoechst $33342(5 \mathrm{mg} / \mathrm{ml})$ in order to determine the total number of sperm cells. Then, slides were washed in PBS. Microscopic images were captured using fluorescence microscopy (Leica DMR, 400x magnification) with appropriate filters $(460-470 \mathrm{nM})$ in a single-blind manner. A minimum of 200 cells were counted and results were expressed in percentage of sperm showing protamine deficiency (\%).

\section{Direct verification of DNA fragmentation by the modified sperm chromatin dispersion assay (SCDA)}

The assay was performed according to the procedure of Shanmugam et al. [37] and Fernández et al. [38]. Initially, the protocol was validated with the use of the sperm-rich fraction collected by digital manipulation from six sexually mature dogs of several breeds. All dogs had proven semen quality, confirmed by previous breeding soundness examination. Only sperm-rich fractions with a minimum of $60 \%$ total sperm motility were used. After sperm collection, one aliquot of each sample was kept at $5{ }^{\circ} \mathrm{C}$ and the remaining sample was exposed to ultraviolet light (Fluxo Veco VLFS-12 M, Campinas, São Paulo) for $4 \mathrm{~h}$ at $25^{\circ} \mathrm{C}$ in order to artificially induce DNA fragmentation. Both aliquots were then mixed to obtain different known proportions of fragmented DNA sperm (0, 25, 50, 75 and 100\%). Sperm smears were subsequently prepared on a glass slide with $10 \mu \mathrm{L}$ of each mixture of damaged/intact DNA sperm. Evaluation of DNA fragmentation was performed using the modified chromatin dispersion assay (SCDA). A minimum of 200 sperm cells were counted and results were expressed as percentage (\%) of DNA fragmented spermatozoa in a single-blind way, i.e., researchers were kept ignorant of either the group they were assessing. A high linear regression coefficient $\left(R^{2}=0.97, p=0.001\right)$ between the observed and the expected percentages of spermatozoa exhibiting DNA damage attested the validation of the SCD assay for dogs (Fig. 1).

For each sperm sample of the present experiment, equal volumes (1:1) of diluted semen $\left(1 \times 10^{6}\right.$ sperm $\left./ \mathrm{mL}\right)$ and $1 \%$ low-melting agarose were mixed at $37^{\circ} \mathrm{C}$. An aliquot of $10 \mu \mathrm{L}$ of this mixture was pipetted on a glass slide coated with $0.65 \%$ normal melting point agarose and subsequently covered with a cover slip and kept for $10 \mathrm{~min}$ at $4^{\circ} \mathrm{C}$ in order to solidify. Immediately after careful removal of the cover slip, the slides were immersed horizontally for $3 \mathrm{~min}$ at $22^{\circ} \mathrm{C}$ in the dark in a tray containing acid denaturation solution $(0.08 \mathrm{~N} \mathrm{HCl})$. This condition generates restricted single-stranded DNA (ssDNA) motifs from DNA breaks. Subsequently, the denaturation was stopped and proteins were removed by transferring the slides for $2 \mathrm{~h}$ at $4{ }^{\circ} \mathrm{C}$ to a tray with neutralizing and lysis solution (10 mM Tris, $4 \mathrm{mM}$ DTT, $2 \%$ Triton X-100, $100 \mathrm{mM} \mathrm{Na} \mathrm{Na}_{2}$ - EDTA, $\left.2.5 \mathrm{M} \mathrm{NaCl}, \mathrm{pH} 11\right)$. The slides were washed in Tris-borate-EDTA buffer $(0.09 \mathrm{M}$ Trisborate and $0.002 \mathrm{M}$ EDTA, $\mathrm{pH}$ 7.5) for $2 \mathrm{~min}$, dehydrated in sequential 70, 90 and 100\% ethanol (2 min each) and, then, air dried. Prepared slides were horizontally covered with a mix of Wright's stain and buffer solution (380 mg Na $\mathrm{PO}_{4}, 547 \mathrm{mg} \mathrm{KH} \mathrm{PO}_{4}$ in $100 \mathrm{~mL}$ distilled water) for $10 \mathrm{~min}$ with continuous air flow. The stain was poured off and slides were briefly washed in tap water and dried.

The stained slides were evaluated under a light microscope and 200 sperm were evaluated per slide for halo size and dispersion pattern at $1000 \times$ magnification in a single-blind manner. The nuclei with large to medium halo size were considered sperms with non-fragmented DNA, while nuclei with small halo size or without halo were considered as sperm cells with fragmented DNA.

\section{Statistical analysis}

All data were evaluated using SAS System for Windows (SAS Institute Inc., Cary, NC, USA). Effects of BPH, 


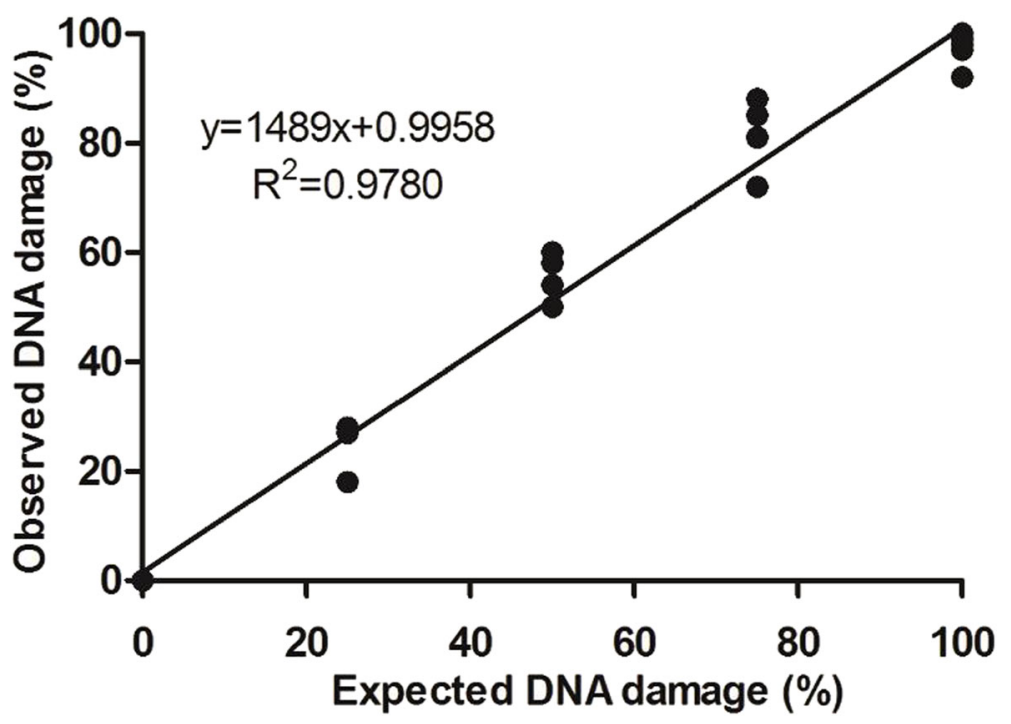

Fig. 1 Linear regression analysis for the sperm chromatin dispersion assay (SCDA) validation for dog sperm

finasteride, moment of evaluation (days 0,30 and 60) and interactions between these factors, were estimated by repeated measures analysis of variance (Mixed Procedure of SAS). If no triple interactions (BPH X finasteride $\mathrm{X}$ Timing) existed, the following interactions were considered: Timing $x$ finasteride, Timing $x \mathrm{BPH}$ and finasteride $x \mathrm{BPH}$. If no dual significant interactions were observed, then effects of groups were analyzed by merging all time points and conversely, time points were compared by combining all groups; otherwise, comparisons were performed taking both effects into account. Differences between $\mathrm{BPH}$ and finasteride treatment were analyzed using parametric and non-parametric tests, according to the residual normality (Gaussian distribution) and variance homogeneity. Data were transformed if one of these assumptions was not respected. When transformations were not successful, non-parametric tests were used. Moreover, differences between BPH and finasteride treatment were analyzed using Student t-test (parametric variables) and Wilcoxon test (nonparametric variables). Results were described as untransformed means \pm SE. The significance level was $P<0.05$.

\section{Results}

No significant triple or dual interaction between time points, BPH diagnosis and finasteride treatment were observed. Hence, the effect of groups was analyzed merging all time points, with special reference to the comparison between BPH and Non-BPH (irrespective of finasteride treatment) and Finasteride and Untreated dogs (regardless of BPH diagnosis).

Sperm DNA integrity was not different between Finasteride and Untreated dogs (Table 1) and time points
(Day 0 vs. Day 30 vs. Day 60). However, BPH dogs had higher susceptibility to DNA fragmentation (1.86 \pm $0.69 \%)$ compared to Non-BPH dogs $(0.3 \pm 0.06 \%$; Fig. $2 a)$. In addition, BPH dogs had higher percentage of DNA fragmentation sperm $(23.2 \pm 4.6 \%)$, compared to the Non-BPH Group (5.3 $\pm 1.3 \%$, Fig. 2b). No significant differences between $\mathrm{BPH}$ and Non-BPH dogs were observed for sperm chromatin dispersion assay (SCDA) and CMA3 (Table 2).

\section{Discussion}

In this study, we have assessed the effects of both Benign Prostatic Hyperplasia (BPH) and finasteride therapy for two consecutive months on sperm DNA integrity in dogs. Despite the relevance of finasteride treatment as an alternative for orchiectomy, only few studies have reported simultaneously the effects of $\mathrm{BPH}$ and finasteride on DNA integrity of dog sperm, leading to insecurity of employing such treatment in BPH breeding dogs.

In men, the use of finasteride causes adverse sperm DNA changes as an important side effect [20]. Conversely, our study demonstrated that the 2 months course of finasteride treatment was not able to cause

Table 1 Mean \pm SE of DNA damaged sperm (\%) of the Finasteride and Untreated Groups

\begin{tabular}{llll}
\hline & Finasteride Treated & Untreated & $P$ \\
\hline SCD & $12 \pm 2.9$ & $14.4 \pm 2.4$ & 0.42 \\
SCSA & $1.8 \pm 0.7$ & $0.4 \pm 0.07$ & 0.07 \\
TB & $17.5 \pm 3.9$ & $11.2 \pm 3.6$ & 0.11 \\
CMA3 & $0.5 \pm 1.2$ & $1.8 \pm 1.6$ & 0.16 \\
\hline
\end{tabular}

SCD sperm chromatin dispersion, SCSA sperm chromatic structure assay, $T B$ toluidine blue stain, CMA3 chromomycinA3 

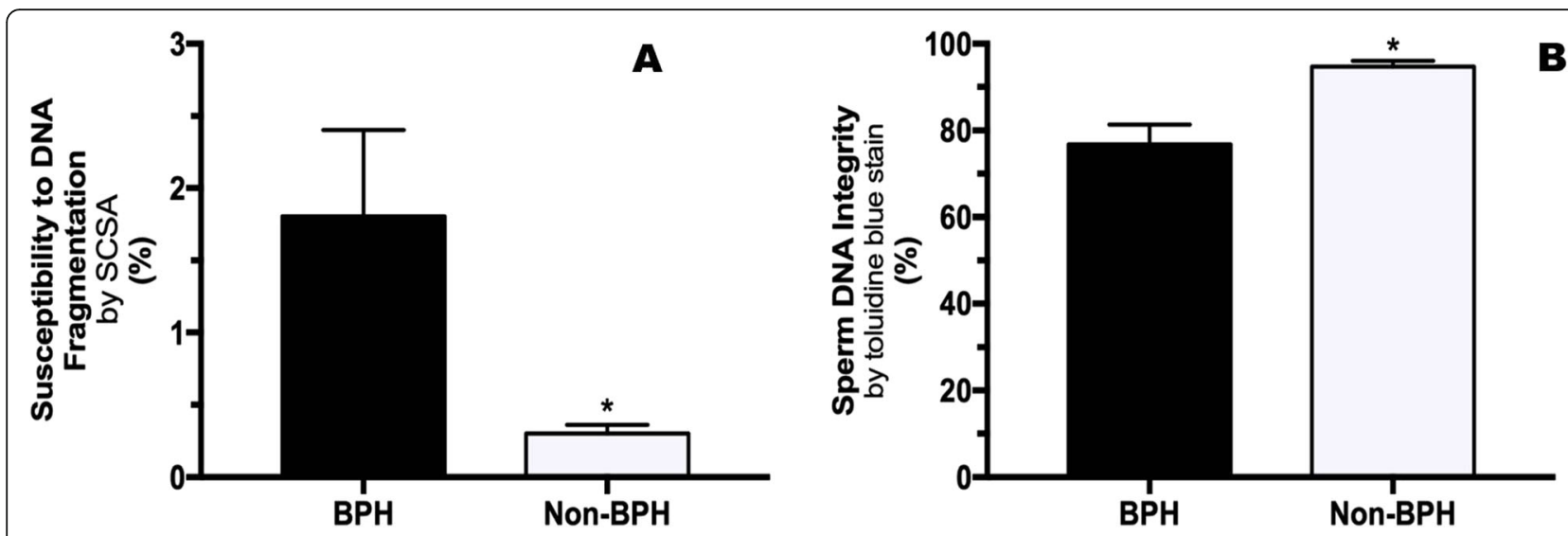

Fig. 2 (a) Susceptibility to DNA fragmentation analysed by the Sperm Chromatic Structure Assay (SCSA) and (b) Toluidine Blue Stain in the BPH and Non-BPH Groups. *indicate significant difference between groups $(P<0.05)$

DNA damage in dog sperm, by means of an overall tracking analysis with SCDA, CMA3, TB and SCSA. We suggest that finasteride detrimental effects in men are related to a dose dependent action, since finasteride posology in dogs is considered to be lower than the one preconized in men, and the time-course of treatment shorter [39]. Thus, we can affirm that the current finasteride protocol ( 2 months course of $5 \mathrm{mg} / \mathrm{dog}$ ) can be safely used without additional adverse effects on sperm DNA integrity, while assuaging clinical signs and reducing prostate size [27]. Additionally, finasteride is recognized to be innocuous for sperm motility and morphology after 4 months of treatment [17]. These data suggest that dogs under finasteride therapy can be safely employed in reproductive programs. However, it is important to point out that a proven fertility screen after finasteride treatment can only be attested if other sperm quality parameters are examined simultaneously [40]. It is of utmost importance to evaluate sperm membrane and acrosome integrity, in addition to chromatin status [41-43].

Albeit finasteride treatment was not able to adversely affect sperm DNA integrity, we showed that BPH dogs have high susceptibility to sperm DNA fragmentation, as observed by SCSA and TB assays. The current finding is of practical importance, since sperm DNA denaturation may be responsible for infertility, abortion, and foetal malformations [30]. Flores et al. [3] and Krakowski et al. [8] have also observed high chromatin instability and

Table 2 Mean \pm SE of DNA damaged sperm (\%) in the BPH and Non-BPH Groups

\begin{tabular}{llll}
\hline & BPH & Non-BPH & $P$ \\
\hline SCDA & $15.8 \pm 2.9$ & $10.5 \pm 2.1$ & 0.42 \\
CMA3 & $8.3 \pm 0.8$ & $9.4 \pm 1.1$ & 0.44 \\
\hline
\end{tabular}

SCD sperm chromatin dispersion, CMA3 chromomycinA3 susceptibility to sperm DNA fragmentation in BPH dogs. Although several conditions may lead to sperm DNA damage [44], changes in the composition of the prostatic fluid are considered one of the main reasons in $\mathrm{BPH}$ dogs [8]. In men, Zabaiou et al. [45] showed that BPH is responsible for oxidative changes of the prostate tissue, accompanied by reduction in prostatic antioxidant concentrations. Accordingly, BPH may also modify the oxidative status of the canine prostatic fluid. In fact, Krakowski et al. [8] showed that the prostatic fluid of BPH dogs has important biochemical alterations, such as high $\mathrm{pH}$, increased cholesterol and decreased zinc and copper concentrations. Zinc deficiency has been associated with DNA fragmentation and oxidative stress, since zinc is a component of the superoxide dismutase, an important antioxidant regulating enzyme $[8,46,47]$. The spermatozoa itself can be a source of reactive oxygen species and, therefore, an autologous adverse effect is triggered. In fact, Vieira et al. [48] reported that oxidative stress is related to sperm mitochondrial malfunction in dogs. Additionally, reduction in sperm mitochondrial activity was observed in $\mathrm{BPH}$ dogs [3]. Taken these data together, we assume that $\mathrm{BPH}$ is responsible for sperm mitochondrial damage, which increases local oxidative stress, ultimately, inducing sperm DNA fragmentation.

Regarding the source of the sperm DNA damage, it is possible to exclude a testicular origin (during spermatogenesis) of the higher susceptibility to sperm DNA fragmentation due to deprotamination [44]. The replacement of sperm DNA histones by protamines results in a more condensed DNA compared to somatic cells [49, 50], consequently higher DNA resistance to damage by external chemical agents and radiation [51]. Since we could not verify differences in CMA3 labelling (i.e., identification of protamine deficient cells) among experimental groups, we suggest that increased susceptibility 
to sperm DNA fragmentation in BPH dogs is not caused by testicular failure of DNA packaging during spermatogenesis and may occur in a post-testicular environment, for example, after the exposure to the seminal plasma [26]. However, further studies are needed in order to evaluate the long-term action of finasteride farther than 65 days, as to compromise a full canine spermatogenic cycle.

In the present study, SCD assay was successfully validated for dogs and further employed to directly evaluate sperm DNA breaks [52], using only light microscopy and easily available chemical reagents, making such analysis accessible to most laboratories. SCD assay allows identifying physical DNA breaks followed by a problem during spermatogenesis or testicular degeneration [26]. However, no difference in SCDA among groups existed in the present experiment, reaffirming the lack of testicular influence on sperm DNA fragmentation in $\mathrm{BPH}$ dogs. Thus, sperm derived from BPH dogs does not show protamination failure or direct DNA damage, albeit a higher susceptibility to DNA fragmentation, which may indicate a role of local alterations of the prostatic fluid. Hence, these data should be taken into account while inducing additional sperm stress as, for example, during sperm cryopreservation and cooling [48].

\section{Conclusion}

In conclusion, sperm of BPH dogs are highly susceptible to DNA fragmentation, which is much likely derived from post-testicular changes of the prostatic fluid. In addition, finasteride treatment is not able to provoke any additional sperm DNA damage. Thus, finasteride can be safely applied in a 2 months course for BPH treatment in dogs, in respect to sperm DNA integrity. To the best of our knowledge, this is the first report to describe the effects of finasteride on sperm DNA integrity in dogs. However, future studies should address the effect of finasteride on an overall panel of sperm quality, including the analysis of sperm plasma membrane and acrosome integrity in BPH dogs, as well as sperm analysis farther than 65 days, trying to reach accurately the entire canine sperm cycle.

\section{Abbreviations}

AO: Acridine orange; BPH: Benign prostatic hyperplasia; CMA3: Chromomycin A3; DHT: Dihydrotestosterone; SCSA: Sperm chromatic structure assay; SCDA: Sperm chromatin dispersion assay; TB: Toluidine Blue

\section{Acknowledgements}

The authors thank Dr. Camilla M Mendes and Prof. Mayra E O A Assumpção for providing support to the flow cytometer analysis; Prof. Ricardo J G Pereira for the TB evaluation.

\section{Authors' contributions}

D.S.R. Angrimani carried out all the evaluations. N. Llamas Luceño and B. Leemans were responsible for the chromomycin A3 evaluation. L.C. Bicudo was responsible for the SCSA evaluation. B.R. Rui and J.D.A. Losano were responsible for the SCDA evaluation. D.S.R. Angrimani and M.F. Silva wrote the manuscript with support from C.I. Vannucchi and A. Van Soom. Moreover, C.I. Vannucchi and A. Van Soom helped supervise the project.
D.S.R. Angrimani conceived the original idea and C.I. Vannucchi supervised the project. The author(s) read and approved the final manuscript.

\section{Funding}

This work was supported by the São Paulo Research Foundation (Fundação de Amparo à Pesquisa do Estado de São Paulo [grant number FAPESP 2015/ 05419-5, 2013/25966-5 and 2017/04102-3]).

\section{Availability of data and materials}

All data generated and analysed during thus study are included in this published article.

\section{Ethics approval and consent to participate}

This study was previously approved by the Bioethics Committee of the School of Veterinary Medicine and Animal Science - University of São Paulo (protocol number: 7122171213). Privately owned dogs of several breeds were used in this study, and the animals were included after the owner consensus.

\section{Consent for publication}

Not applicable.

\section{Competing interests}

The authors declare that they have no competing interests.

\section{Author details}

${ }^{1}$ Department of Animal Reproduction, School of Veterinary Medicine and Animal Science, University of São Paulo, Av. Prof. Orlando Marques de Paiva, 87, São Paulo 05508-270, Brazil. ²Department of Reproduction, Obstetrics and Herd Health, Faculty of Veterinary Medicine, Ghent University, 9820 Merelbeke, Belgium.

Received: 18 May 2020 Accepted: 30 June 2020

Published online: 16 July 2020

\section{References}

1. Kim BH, Kim Cl, Chang HS, Choe MS, Jung HR, Kim DY, et al. Cyclooxygenase-2 overexpression in chronic inflammation associated with benign prostatic hyperplasia: is it related to apoptosis and angiogenesis of prostate cancer? Korean J Urol. 2001. https://doi.org/10.4111/kju.2011.52.4.253.

2. Memon MA. Common causes of male dog infertility. Theriogenology. 2007. https://doi.org/10.1016/j.theriogenology.2007.04.025.

3. Flores RB, Angrimani DSR, Rui BR, Brito MM, Abreu RA, Vannucchi Cl. The influence of benign prostatic hyperplasia on sperm morphological features and sperm DNA integrity in dogs. Reprod Domest Anim. 2016. https://doi. org/10.1111/rda.12817

4. Lotti F, Tamburrino L, Marchiani S, Maseroli E, Vitale P, Forti G, et al. DNA fragmentation in two cytometric sperm populations: relationship with clinical and ultrasound characteristics of the male genital tract. Asian J Androl. 2016. https://doi.org/10.4103/1008-682X.174854.

5. Wolf K, Kayacelebi H, Urhausen C, Piechotta M, Mischke R, Kramer S, et al. Testicular steroids, prolactin, Relaxin and prostate gland markers in peripheral blood and seminal plasma of Normal dogs and dogs with prostatic hyperplasia. Reprod Domest Anim. 2012. https://doi.org/10.1111/ rda.12083.

6. Carson C, Rittmaster $\mathrm{R}$. The role of dihydrotestosterone in benign prostatic hyperplasia. Urology. 2003. https://doi.org/10.1016/S0090-4295(03)00045-1.

7. Wdowiak A, Raczkiewicz D, Stasiak M, Bojar I. Levels of FSH, LH and testosterone, and sperm DNA fragmentation. Neuro Endo Lett. 2014:35:73-9.

8. Krakowski L, Wachocka A, Brodzki P, Wrona Z, Piech T, Wawron W, et al. Sperm quality and selected biochemical parameters of seminal fluid in dogs with benign prostatic hyperplasia. Anim Reprod Sci. 2015. https://doi.org/10. 1016/j.anireprosci.2015.07.014.

9. Li LF, Wang H, Zhang J, Ma C, Li YY, Wang L, et al. Syntheses, characterization, interaction with DNA, cytotoxic and apoptosis of two novel complexes of Zn (II) and Mn (II) with 2-methyl-1H-4,5imidazoledicarboxylic acid. Eur J Med Chem. 2015. https://doi.org/10.1016/j. ejmech.2014.12.042.

10. Pace G, Massimo C, Amicis D, Corbacelli C, Di Renzo L, Vicentini C, et al. Oxidative stress in benign prostatic hyperplasia and prostate cancer. Urol Int. 2010. https://doi.org/10.1159/000366210. 
11. Tsutsui T, Hori T, Shimizu M, Tatsuzawa C, Kawakami E. Effect of Osaterone acetate administration on prostatic regression rate, peripheral blood hormone levels and semen quality in dogs with benign prostatic hypertrophy. J Vet Med Sci. 2001. https://doi.org/10.1292/jvms.63.453.

12. Christensen BW. Canine prostate disease. Veterinary Clinics of North America: Small Animal Practice; 2018. https://doi.org/10.1016/j.cvsm.2018.02.012.

13. Socha P, Zduńczyk S, Tobolski D, Janowski T. The effects of osaterone acetate on clinical signs and prostate volume in dogs with benign prostatic hyperplasia. Pol J Vet Sci. 2018. https://doi.org/10.24425/pjvs.2018.125601.

14. Cunto M, Mariani E, Anicito EG, Ballotta G, Zambelli D. Clinical approach to prostatic diseases in the dog. Reprod Domest Anim. 2018. https://doi.org/ 10.1111/rda.13437.

15. Kaplan SA. 5Alpha-Reductase inhibitors: what role should they play? Urology. 2001. https://doi.org/10.1016/S0090-4295(01)01347-4.

16. Laroque PA, Prahalada S, Gordon LR, Noblot SM, Bagdon WJ, Duprat P, et al. Effects of chronic Oral-Administration of a Selective 5-alpha-Reductase inhibitor, finasteride, on the dog prostate. Prostate. 1994. https://doi.org/10. 1002/pros.2990240207.

17. Sirinarumitr K, Johnston SD, Kustritz MVR, Johnston GR, Sarkar DK, Memon MA. Effects of finasteride on size of the prostate gland and semen quality in dogs with benign prostatic hypertrophy. J Am Vet Med Assoc. 2001. https:// doi.org/10.2460/javma.2001.218.1275.

18. Iguer-Ouada M, Verstegen JP. Effect of finasteride (Proscar MSD) on seminal composition, prostate function and fertility in male dogs. J Reprod Infertil. 1995;51:139-49.

19. Chiba K, Yamaguchi K, Li F, Ando M, Fujisawa M. Finasteride-associated male infertility. Fertil Steril. 2011. https://doi.org/10.1016/j.fertnstert.2010.12.001.

20. Tu HY, Zini A. Finasteride-induced secondary infertility associated with sperm DNA damage. Fertil Steril. 2011. https://doi.org/10.1016/j.fertnstert. 2010.12.061.

21. Glina S, Neves PA, Saade R, Netto NR, Soares JB, Galuppo AG. Finasterideassociated male infertility. Rev Hosp Clin Fac Med Sao Paulo. 2004;59: 203-5.

22. Vidigal DJA, Silva AL, Fonseca LMA, Vasconcelos AC, Resende DF, Vidigal FEC. The effect of finasteride on spermatogenesis of Mesocricetus auratus. Acta Bras Cir. 2008. https://doi.org/10.1590/S0102-86502008000300012.

23. Lewis SE, Aitken JR, Conner SJ, Iuliis GD, Evenson DP, Henkel R, et al. The impact of sperm DNA damage in assisted conception and beyond: recent advances in diagnosis and treatment. Reprod BioMed Online. 2013. https:// doi.org/10.1016/j.rbmo.2013.06.014.

24. Simoes R, Feitosa WB, Siqueira AF, Nichi M, Paula-Lopes FF, Marques MG, et al. Influence of bovine sperm DNA fragmentation and oxidative stress on early embryo in vitro development outcome. Reprod. 2013. https://doi.org/ 10.1530/REP-13-0123.

25. Simon L, Brunborg G, Stevenson M, Lutton D, McManus J, Lewis SE. Clinical significance of sperm DNA damage in assisted reproduction outcome. Hum Reprod. 2010. https://doi.org/10.1093/humrep/deq103.

26. Iommiello VM, Albani E, Rosa A, Marras A, Menduni F, Morreale G, et al. Ejaculate oxidative stress is related with sperm DNA fragmentation and round cells. Int J Endocrinol. 2015. https://doi.org/10.1155/2015/321901.

27. Angrimani DSR, Silvestrini GR, Brito MM, Abreu RA, Almeida LL, Vannucchi CI. Effects of benign prostatic hyperplasia and finasteride therapy on prostatic blood flow in dogs. Theriogenology. 2018. https:/doi.org/10.1093/ps/81.9.1347.

28. Zelli R, Orlandi R, Troisi A, Cardinali L, Polisca A. Power and pulsed Doppler evaluation of prostatic artery blood flow in normal and benign prostatic hyperplasia-affected dogs. Reprod Domest Anim. 2013. https://doi.org/10. 1111/rda.12159.

29. Pasikowska J, Hebel M, Nizanski W, Nowak M. Computed tomography of the prostate gland in healthy intact dogs and dogs with benign prostatic hyperplasia. Reprod Domest Anim. 2015. https://doi.org/10.1111/rda.12587.

30. Kamolpatana K, Johnston SD, Hardy SK, Castner S. Effect of finasteride on serum concentrations of dihydrotestosterone and testosterone in three clinically normal sexually intact adult male dogs. Am J Vet Med Res. 1998:59:762-4.

31. Rui BR, Angrimani DSR, Bicudo LC, Losano JDA, Nichi M, Pereira RJG. A fast, low-cost and efficient method for the diagnosis of sperm DNA fragmentation in several species. Reprod Domest Anim. 2018. https://doi. org/10.1111/rda.13087.

32. Lucio CF, Regazzi FM, Silva LC, Angrimani DS, Nichi M, et al. Oxidative stress at different stages of two-step semen cryopreservation procedures in dogs. Theriogenology. 2016. https://doi.org/10.1016/j.theriogenology.2016.01.016.
33. Evenson DP, Jost LK, Marshall D, Zinaman MJ, Clegg E, Purvis K, et al. Utility of the sperm chromatin structure assay as a diagnostic and prognostic tool in the human fertility clinic. Hum Reprod. 1999. https://doi.org/10.1093/ humrep/14.4.1039.

34. Minervini F, Guastamacchia R, Pizzi F, Dell'Aquila ME, Barile VL. Assessment of different functional parameters of frozen-thawed buffalo spermatozoa by using cytofluorimetric determinations. Reprod Domest Anim. 2013. https:// doi.org/10.1111/j.1439-0531.2012.02152.x.

35. Rahman MB, Kamal MM, Rijsselaere T, Vandaele L, Shamsuddin M, Soom AV. Altered chromatin condensation of heat-stressed spermatozoa perturbs the dynamics of DNA methylation reprogramming in the paternal genome after in vitro fertilisation in cattle. Reprod Fertil Dev. 2014. https://doi.org/10. 1071/RD13218.

36. Simões R, Feitosa WB, Mendes CM, Marques MG, Nicacio AC, Barros FRO, et al. Use of chromomycin A3 staining in bovine sperm cells for detection of protamine deficiency. Biotech Histochem. 2009. https://doi.org/10.1080/ 10520290902843595.

37. Shanmugam M, Vinoth A, Rajaravindra KS, Rajkumar U. Evaluation of semen quality in roosters of different age during hot climatic condition. Anim Reprod Sci. 2014. https://doi.org/10.1016/j.anireprosci.2013.12.015.

38. Fernandez JL, Muriel L, Rivero MT, Goyanes V, Vazquez R, Alvarez JG. The sperm chromatin dispersion test: a simple method for the determination of sperm DNA fragmentation. J Androl. 2003. https://doi.org/10.1002/j.1939-4640.2003.tb02641.x.

39. Mysore V. Finasteride and sexual side effects. Indian J Dermatol. 2012. https://doi.org/10.4103/2229-5178.93496.

40. Lange-Consiglio A, Antonucci N, Manes S, Corradetti B, Cremonesi F, Bizzaro D. Morphometric characteristics and chromatin integrity of spermatozoa in three Italian dog breeds. J Small Anim Pract. 2010. https://doi.org/10.1111/j. 1748-5827.2010.01001.x.

41. Bencharif $D$, Amirat $L$, Anton M, Schmitt E, Desherces S, Delhomme $G$, et al. The advantages of LDL (low density lipoproteins) in the cryopreservation of canine semen. Theriogenology. 2008. https://doi.org/10.1016/j. theriogenology.2008.06.095.

42. Choi BS, Kim TK, Hyun C. Chromatin assays for DNA fragmentation evaluation in canine sperm. J Anim Vet Adv. 2011. https://doi.org/10.3923/ javaa.2011.1501.1503.

43. Evenson DP, Darzynkiewicz Z, Melamed MR. Relation of mammalian sperm chromatin heterogeneity to fertility. Science. 1980. https://doi.org/10.1126/ science. 7444440

44. Sakkas D, Alvarez JG. Sperm DNA fragmentation: mechanisms of origin, impact on reproductive outcome, and analysis. Fertil Steril. 2010. https://doi. org/10.1016/j.fertnstert.2009.10.046.

45. Zabaiou N, Mabed D, Lobaccaro JM, Lahouel M. Oxidative stress in benign prostate hyperplasia. Andrologia. 2016. https://doi.org/10.1093/jn/138.4.667.

46. Björndahl L, Kvist U. A model for the importance of zinc in the dynamics of human sperm chromatin stabilization after ejaculation in relation to sperm DNA vulnerability. Syst Biol Reprod Med. 2011. https://doi.org/10.3109/ 19396368.2010 .516306

47. Yan M, Song Y, Wong CP, Hardin K, Ho E. Zinc deficiency alters DNA damage response genes in normal human prostate epithelial cells. J Nutr. 2008. https://doi.org/10.1093/jn/138.4.667.

48. Vieira NMG, Losano JDA, Angrimani DSR, Kawai GKV, Bicudo LC, Rui BR, et al. Induced sperm oxidative stress in dogs: susceptibility against different reactive oxygen species and protective role of seminal plasma. Theriogenology. 2018. https://doi.org/10.1016/j.theriogenology.2017.11.020.

49. Manicardi GC, Bianchi PG, Pantano S, Azzoni P, Bizzaro D, Bianchi U, et al. Presence of endogenous nicks in DNA of ejaculated human spermatozoa and its relationship to chromomycin A3 accessibility. Biol Reprod. 1995;52:864-7.

50. Ward WS, Coffey DS. DNA packaging and Organization in Mammalian Spermatozoa: comparison with somatic cells. Biol Reprod. 1991. https://doi. org/10.1095/biolreprod44.4.569.

51. Bizzaro D, Manicardi GC, Bianchi PG, Bianchi U, Mariethoz E, Sakkas D. In-situ competition between protamine and fluorochromes for sperm DNA. Mol Hum Reprod. 1998:4:127-32.

52. Gosálvez J, López-Fernández C, Fernández J, Esteves S, Johnston S. Unpacking the mysteries of sperm DNA fragmentation. J Reprod Biot Fert. 2015. https://doi.org/10.1177/2058915815594454.

\section{Publisher's Note}

Springer Nature remains neutral with regard to jurisdictional claims in published maps and institutional affiliations. 